\title{
Dynamic involvement of ATG5 in cellular stress responses
}

\author{
HH Lin ${ }^{1}$, S-M Lin ${ }^{1}$, Y Chung ${ }^{1}$, S Vonderfecht ${ }^{2}$, JM Camden ${ }^{3}$, P Flodby ${ }^{4}$, Z Borok ${ }^{4,5}$, KH Limesand $^{6}$, N Mizushima ${ }^{7}$ and DK Ann ${ }^{\star, 1,8}$
}

Autophagy maintains cell and tissue homeostasis through catabolic degradation. To better delineate the in vivo function for autophagy in adaptive responses to tissue injury, we examined the impact of compromised autophagy in mouse submandibular glands (SMGs) subjected to main excretory duct ligation. Blocking outflow from exocrine glands causes glandular atrophy by increased ductal pressure. Atg $5^{f /-} ;$;qp5-Cre mice with salivary acinar-specific knockout (KO) of autophagy essential gene Atg5 were generated. While duct ligation induced autophagy and the expression of inflammatory mediators, SMGs in Atg $5^{t /-} ;$ Aqp 5 -Cre mice, before ligation, already expressed higher levels of proinflammatory cytokine and Cdkn1a/p21 messages. Extended ligation period resulted in the caspase-3 activation and acinar cell death, which was delayed by Atg5 knockout. Moreover, expression of a set of senescence-associated secretory phenotype (SASP) factors was elevated in the post-ligated glands. Dysregulation of cell-cycle inhibitor CDKN1A/p21 and activation of senescence-associated $\beta$-galactosidase were detected in the stressed SMG duct cells. These senescence markers peaked at day 3 after ligation and partially resolved by day 7 in post-ligated SMGs of wild-type (WT) mice, but not in KO mice. The role of autophagy-related 5 (ATG5)-dependent autophagy in regulating the tempo, duration and magnitude of cellular stress responses in vivo was corroborated by in vitro studies using MEFs lacking ATG5 or autophagy-related 7 (ATG7) and autophagy inhibitors. Collectively, our results highlight the role of ATG5 in the dynamic regulation of ligation-induced cellular senescence and apoptosis, and suggest the involvement of autophagy resolution in salivary repair.

Cell Death and Disease (2014) 5, e1478; doi:10.1038/cddis.2014.428; published online 23 October 2014

Autophagy is a catabolic process that has an essential role in cellular adaptation to multiple types of stress by recycling of superfluous cellular material, safeguarding quality control in organelles, removing protein aggregates, and eliminating intracellular pathogens. ${ }^{1}$ Conceptually, autophagy serves a pro-survival mechanism by providing sources of energy and biosynthetic building blocks during starvation, removing dysfunctional organelles and large aggregates toxic to cells to avoid unwarranted cell death. However, upon sustained stress conditions, cell death eventually takes place either by excessive autophagy or by the induction of apoptosis and/or necrosis pathways. ${ }^{2}$ The ATG5, autophagy-related 5 , has a pivotal role in autophagosome formation. Mouse neonates systemic deficient for ATG5 die within a day of birth, ${ }^{3}$ whereas mice depleted of Atg5 in selected tissues have abnormalities ranging from neurodegeneration ${ }^{4}$ and age-related cardiomyopathy ${ }^{5}$ to liver tumors. ${ }^{6}$

Autophagy and senescence are two distinct, however functionally intertwined, cellular responses to stress. ${ }^{7}$ Cellular senescence is a state of stable growth arrest that is induced by telomere shortening, DNA-damage, oncogenes or other stresses. In general, senescence is a heterogeneous phenotype, which is characterized by a senescent-associated secretory phenotype (SASP), expression of senescenceassociated $\beta$-galactosidase (SA- $\beta$-gal) and other senescent markers, and increased cell size. ${ }^{8}$ In culture system, inhibiting or enhancing autophagy leads to the opposite effect on premature senescence. ${ }^{9-12}$ While premature senescence can be induced by a plethora of cell-extrinsic and cell-intrinsic stressors, ${ }^{13}$ little is known about the possible role of autophagy in modulating injury-induced cellular senescence in vivo. Rodent salivary duct ligation has been used as an experimental model system to study salivary gland atrophy, which often occurs in patients with Sjögren's syndrome or receiving head and neck radiation therapy. Although autophagy induction has been implicated in the repair of rapamycin-treated, post-ligated salivary glands, ${ }^{14,15}$ the roles played by

\footnotetext{
${ }^{1}$ Department of Molecular Pharmacology, Beckman Research Institute, City of Hope, Duarte, CA, USA; ${ }^{2}$ Division of Comparative Medicine, Beckman Research Institute, City of Hope, Duarte, CA, USA; ${ }^{3}$ Department of Biochemistry, University of Missouri, Columbia, MO, USA; ${ }^{4}$ Division of Pulmonary, Critical Care and Sleep Medicine, Department of Medicine, Will Rogers Institute Pulmonary Research Center, Keck School of Medicine, University of Southern California, Los Angeles, CA, USA; ${ }^{5}$ Department of Biochemistry and Molecular Biology, Keck School of Medicine, University of Southern California, Los Angeles, CA, USA; ${ }^{6}$ Department of Nutritional Sciences, The University of Arizona, Tucson, AZ, USA; ${ }^{7}$ Department of Biochemistry and Molecular Biology, The University of Tokyo, Bunkyo-ku, Tokyo, Japan and ${ }^{8}$ Irell \& Manella Graduate School of Biological Sciences, Beckman Research Institute, City of Hope, Duarte, CA, USA

${ }^{*}$ Corresponding author: DK Ann, Department of Molecular Pharmacology, Beckman Research Institute, City of Hope, 1500 East Duarte Road, Duarte, 91010 CA, USA. Tel: + 16263598111 Ext. 64967; Fax: +1 1626471 7204; E-mail: dann@coh.org

Abbreviations: AQP5, aquaporin 5; ATG5, autophagy-related 5; ATG7, autophagy-related 7; BafA1, bafilomycin A1; Bcl2/11/Bim, Bcl2-like 11; Bmf, Bcl2 modifying factor; Casp3, caspase-3; Ccl2/MCP-1, chemokine (C-C motif) ligand 2/monocyte chemoattractant protein-1; Cdkn, cyclin-dependent kinase inhibitor; CQ, chloroquine; ELISA, enzyme-linked immunosorbent assay; Gclc, glutamate-cysteine ligase, catalytic subunit; GCD, granular convoluted duct; GFP, green fluorescent protein; II1, interleukin 1; II6, interleukin 6; Ifng, interferon gamma; KO, knockout; KIk1, kallikrein 1; MAP1LC3, microtubule-associated protein 1 light chain 3; Nqo1, NADPH dehydrogenase, quinone 1; Prol1/Muc-10, proline rich, lacrimal 1/mucin-10; Ptgs2/Cox-2, prostaglandin-endoperoxide synthase 2/cyclooxygenase 2; RFP, red fluorescent protein; Sqstm1/ p62, sequestosome 1; SA- $\beta$-gal, senescence-associated $\beta$-galactosidase; SASP, senescence-associated secretory phenotype; SMG, submandibular gland; Tnf, tumor necrosis factor; WT, wild type
}

Received 07.5.14; revised 05.9.14; accepted 05.9.14; Edited by S Lavandero 
autophagy in regulating the injury responses in submandibular glands (SMGs) have not been explored.

To explore how autophagy contributes to salivary (patho) physiology, we established a transgenic mouse model deficient for ATG5 in the salivary acinar cells. Previously, we have identified a role for basal autophagy in salivary homeostatic mechanisms that restrict acinar cell size and the number of secretory granules. ${ }^{16}$ Here, we report that ligation of the major SMG excretory duct triggers the glandular atrophy and the induction of autophagy. By comparing the acute and subacute stress responses from autophagy-impaired and -competent SMGs with duct obstruction, we established the intrinsic roles of ATG5-dependent autophagy in modulating salivary inflammatory responses, stress-induced senescence and cell death, which all occur sequentially in response to tissue injury. Our results provide in vivo evidence that stress-induced autophagic response is indispensable for resolving premature senescence in duct cells of the ligated glands, whereas ATG5 deficiency leads to delayed acinar cell death.

\section{Results}

Acinar-specific autophagy deficiency. To assess the contribution of autophagy to tissue injury, we impaired Atg5 expression in salivary acinar cells by crossing mice expressing aquaporin 5 (Aqp5)-driven Cre recombinase ${ }^{17}$ with mice containing loxP sites that flank the third exon of $A \operatorname{tg} 5^{4}$ (Figure 1a) and subjected these mice to ductal ligation. Expression of the Aqp5-Cre transgene mirrored endogenous Aqp5 in the salivary glands and was acinar cell specific. ${ }^{17}$ Immunohistochemical $(\mathrm{IHC})$ analyses revealed that ATG5 expression was not only abolished in AQP5-expressing acinar cells, but also decreased substantially in AQP5 non-expressors, mainly granular convoluted ducts (GCDs) and other duct cells in the SMGs of $A \operatorname{tg} 5^{f /-}$;Aqp5-Cre mice (Figure 1b). This is because offspring from Atg $^{+/-} ;$Aqp5-Cre and Atg5 ${ }^{f / f}$ crossbreeds exhibited an ATG5 hypomorphic phenotype in SMGs (Figure 1c, +/+ versus F/F) introduced by the flox allele. ${ }^{18}$ As expected, higher ATG5-ATG12 signals were coexisted with higher abundance of lipidated microtubuleassociated protein 1 light chain 3 (MAP1LC3-II) (and lower MAP1LC3-I) in the SMGs of $A \operatorname{tg} 5^{+/+}$mice compared with those of $A \operatorname{Atg} 5^{\mathrm{F} / \mathrm{F}}, \quad \operatorname{Atg} 5^{\mathrm{F} /-}$ or $A \operatorname{Atg} 5^{\mathrm{F} /-} ;$ Aqp5-Cre mice (Figure 1c). In the ensuing studies, Atg $5^{f /+} ;$ Aqp5-Cre mice (designated as Atg5 ${ }^{\mathrm{WT}}$ ) and acinar cell-specific Atg5-knockout mice, $\operatorname{Atg} 5^{\mathrm{f} /-} ;$ Aqp5-Cre (designated as $\operatorname{Atg} 5^{\mathrm{KO}}$ ) were used to simultaneously explore the effects of ATG5 deficiency in acinar cells and reduced ATG5 level in duct cells of SMGs. To document the effect of compromised autophagy on basal gene expression in SMGs, quantitative RT-PCR analyses on message abundance from selected injury response and other genes were performed. Notably, the expression of the proinflammatory mediators such as $1 / 6,1 / 1 b$, Tnf and Ifng was significantly elevated in SMGs of KO mice (Figure 1d).

SMG duct ligation induces autophagy. Next, we investigated whether tissue injury by ligating SMG main excretory ducts from $A \operatorname{tg} 5^{\mathrm{WT}}$ and $A \operatorname{tg} 5^{\mathrm{KO}}$ mice for 1, 3 and 7 days induced autophagy. As expected, the MAP1LC3-interacting sequestosome 1/p62 (SQSTM1), a cargo-recognition protein for autophagy was readily detectable in control SMGs of Atg $5^{\kappa \mathrm{O}}$, but not $A \operatorname{tg} 5^{\mathrm{WT}}$ mice (Figure 2a, lane 5 versus lane 1). During ligation, MAP1LC3-II levels increased in Atg5 ${ }^{\mathrm{NT}}$ SMGs at day 1 and remained high throughout the time course (Figure 2a,Supplementary Figure S1A). Additionally, steadystate levels of SQSTM1 were undetectable in control and duct-ligated $\operatorname{Atg} 5^{\mathrm{NT}}$ SMGs at day 1, but increased at day 3 (Figure 2a,Supplementary Figure S1B). Notably, SQSTM1 accumulated extensively in the ligated glands from $\operatorname{Atg}^{\mathrm{KO}}$ mice (Figure 2b,Supplementary Figure S1C). On the basis of comparable Sqstm1 mRNA levels between these two genotypes, both basal and post-ligation (Figure 1d, Supplementary Figure S2), and sustained accumulation of SQSTM1 protein in ligated SMGs of $A \operatorname{tg} 5^{\mathrm{KO}}$ mice, we conclude that duct ligation induced autophagy in SMGs.

As depleting ATG5 affected basal abundance of proinflammatory response messages (Figure 1d), the expression of selected inflammatory mediators, including proinflammatory cytokines, II6, $/ / 1 a, \| 1 b$, Tnf and Ifng, and prostaglandinendoperoxide synthase 2/cyclooxygenase 2 (Ptgs2/Cox-2) in the post-ligated SMGs of $\operatorname{Atg} 5^{\mathrm{NT}}$ and $\operatorname{Atg} 5^{\mathrm{KO}}$ mice was assessed. We found that duct ligation caused robust increases in these mRNA abundances as early as day 1 post ligation in both genotypes, and the inactivation of ATG5 only affected relative $\mathrm{Bcl} 2$ modifying factor $(\mathrm{Bmf})$ message induction in the ligated SMGs of $A \operatorname{tg} 5^{\mathrm{KO}}$ mice compared with $A \operatorname{tg} 5^{\mathrm{NT}}$ mice after 1 day of ligation (Supplementary Figure S2). There was an over 300-fold increase in $1 / 6$ mRNA abundance in ductligated SMGs of $A \operatorname{tg} 5^{\kappa \circ}$ mice at day 1 , followed by a decline. Similar patterns of $1 / 1 a, 1 / 1 b$ and Ptgs2/Cox-2 mRNAs surges of different magnitudes were observed in ligated SMGs of $\operatorname{Atg} 5^{\mathrm{KO}}$ mice. To validate induction of proinflammatory cytokines, we measured TNF- $a$ protein level by enzyme-linked immunosorbent assay (ELISA). TNF- $a$ level peaked in L3 SMG from both genotypes at approximately $1.5 \mathrm{ng} / \mathrm{mg}$ total protein.

\section{Autophagy alters duct ligation-induced morphological} manifestations. Gross examination revealed that SMG size of $A \operatorname{tg} 5^{K O}$ mice increased initially at day 1 , which could be due to a combination of obstructed saliva outflow and an inflammatory response then leveled off at day 3 and atrophied at day 7 after duct ligation (Supplementary Figure S3). In comparison, significant glandular weight loss was detected in ligated SMGs of $A \operatorname{tg} 5^{\mathrm{WT}}$ mice at day 3 post ligation (Supplementary Figure S3I). On average, we observed 19\% decrease in gland weight compared with the contralateral ligation control SMG in the same mouse, and the degree of atrophy in terms of weight loss was indistinguishable between $\operatorname{Atg} 5^{\mathrm{NT}}$ and $\operatorname{Atg}^{\mathrm{KO}}$ mice at day 7 post ligation (Supplementary Figure S3I). However, gland weights of $A \operatorname{tg} 5^{\mathrm{KO}}$ mice were slightly higher than that of $A \operatorname{tg} 5^{\mathrm{NT}}$ mice at day 3 post ligation. Microscopically, GCD cells lost many secretory granules and exhibited a dilated phenotype after ligation (Figure 2c). Extensive dilation of ductal system, presumably overloaded with saliva as a result of the outflow obstruction, was particular pronounced in L1 and L3 SMGs of $A \operatorname{tg} 5^{\mathrm{WT}}$ mice and to a lesser extent in $A \operatorname{tg} 5^{\kappa \circ}$ mice (Figure 2c). The level of duct dilation reduced slowly toward baseline from day 3 to 
a

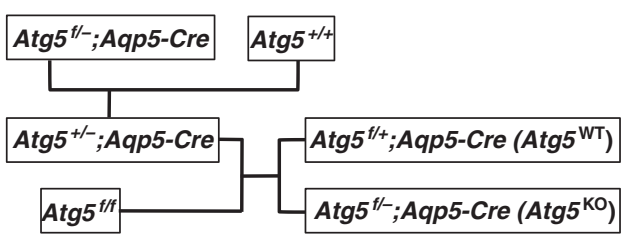

b

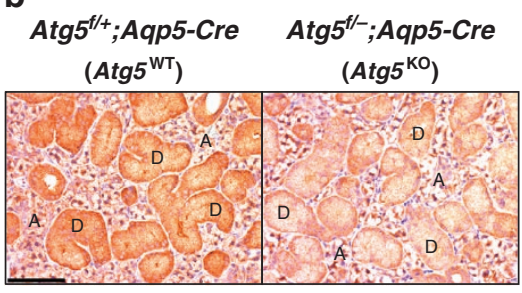

C

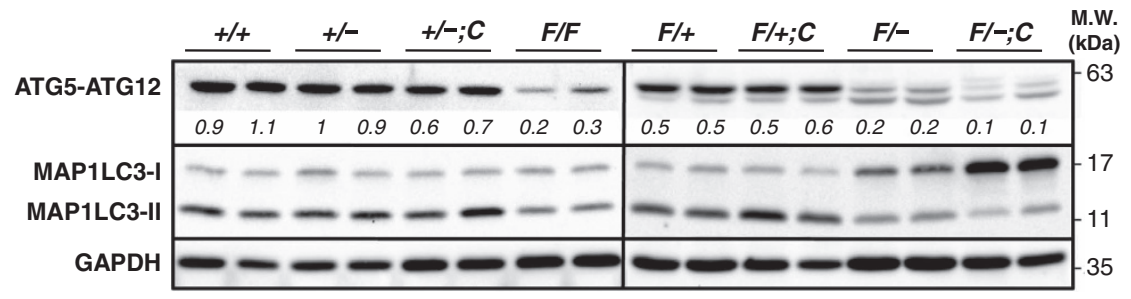

d $\square \operatorname{Atg} 5^{\mathrm{WT}}-\operatorname{Atg} 5^{\mathrm{KO}}$

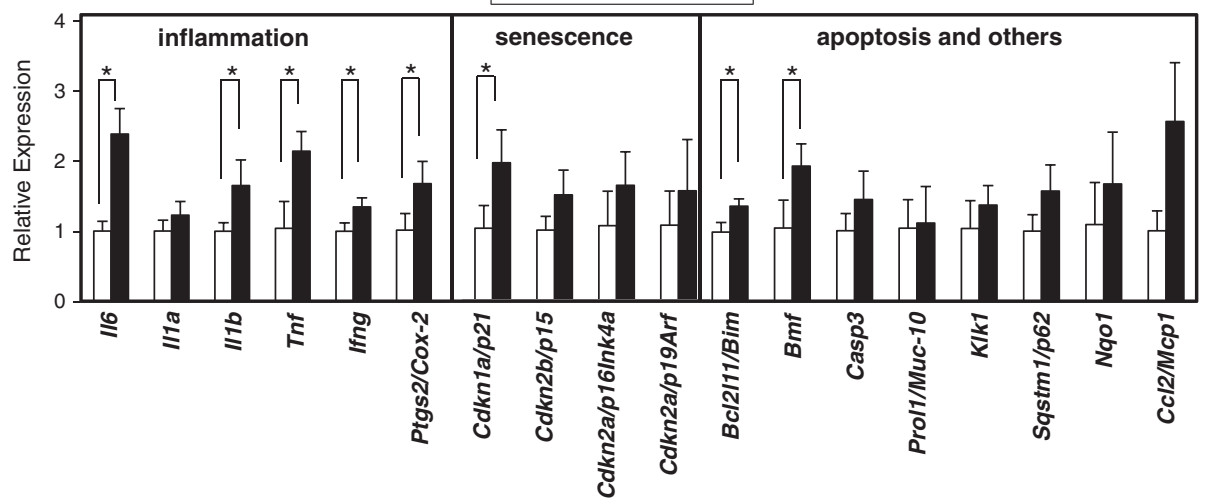

Figure 1 Elevated basal expression of proinflammatory cytokines genes in Atg5-knockout SMGs. (a) Schematic diagram of generation of experimental mice. Mice developed

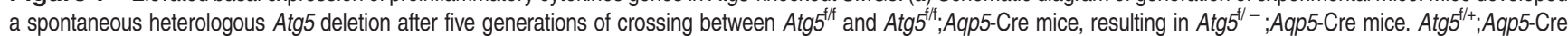
$\left(\right.$ Atg $\left.^{5 T}\right)$ and $A \operatorname{tg} 5^{5 /} ;$;qp5-Cre $\left(A t g 5^{K o}\right)$ mice were used in studies herein. (b) Immunohistochemical analyses show decreased ATG5 protein in both SMG granular convoluted ducts (GCDs; labeled D) and acinar cells (labeled A) of Atg $5^{\kappa 0}$ mice, compared with that of Atg $5^{\omega T}$ mice. Bar: $100 \mu \mathrm{m}$. (c) Correlation of decreased ATG5 expression and impaired MAP1LC3 lipidation in SMGs among different genotypes. Equal amounts of whole SMG lysates from two individual mouse of the indicated genotype were analyzed for ATG5 and MAP1LC3 levels by western blots. ATG5 expression was greatly reduced in the SMGs of $A \operatorname{tg} 5^{\mathrm{F} / \mathrm{F}}$ than that in $A \operatorname{tg} 5^{+/+}$mice. This hypomorphic phenotype in floxed mouse line

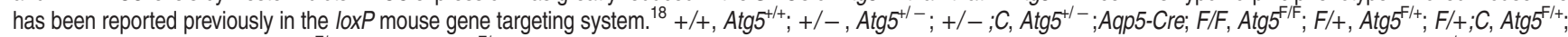

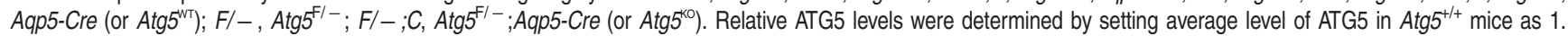
(d) Quantitative RT-PCR analyses show elevated basal expression of selected proinflammatory cytokine genes in SMGs from Atg $5^{\kappa O}$ mice. Respective mean expression level of the indicated message from SMGs of $A \operatorname{Atg} 5^{\text {WT }}$ mice was set as 1 . Results are shown as mean \pm S.D.; $N=3$; ${ }^{\star} P<0.05$

day 7 post ligation. In parallel, secretory acinar cells became enlarged and were staining pale from lacking eosinophilic cytoplasmic staining at day 1 in both genotypes (Figure 2c, $L 1$ inset). By day 3 , enlarged acinar cells remained in SMGs of $\operatorname{Atg}^{\mathrm{KO}}$ mice (Figure 2c, L3, arrowheads); however, they were relatively sparse in the L3 SMGs of $\operatorname{Atg}^{\mathrm{NT}}$ mice (Supplementary Figure S4A). By day 7, the atrophied glands from both $\operatorname{Atg} 5^{\mathrm{WT}}$ and $\operatorname{Atg} 5^{\mathrm{KO}}$ mice had residual GCD structures and scattered acinar cells (Figure 2c, Supplementary Figure S4A). Furthermore, in agreement with the observation of robust inflammatory responses (Supplementary Figure S1), trichrome staining revealed extensive tissue fibrosis in SMGs following prolonged ligation (Figure 2d,Supplementary Figure S4B). Mucin-like material (non-eosinophilic staining) accumulated in acinar cells of $L 1$ SMGs from both genotypes and L3 SMGs from $\operatorname{Atg}^{\mathrm{Ko}}$ mice only, but not $A \operatorname{tg} 5^{\mathrm{WT}}$ mice. Similar to H \& E staining, trichrome staining revealed more severe fibrosis in L3 SMGs of $\operatorname{Atg}^{\mathrm{NT}}$ mice than the corresponding SMGs of $A \operatorname{tg} 5^{\kappa \circ}$ mice (Figure 2d,Supplementary Figure S4B).

To confirm the loss of acinar cells in duct-ligated L3 SMGs of $\operatorname{Atg} 5^{\mathrm{WT}}$ mice, we examined red and green fluorescence patterns in duct-ligated SMGs of $\mathrm{mT} / \mathrm{mG}$;Aqp5-Cre reporter mice (Figure 3a). As expected, acinar cells had a distinct pattern of green $\mathrm{mG}$ fluorescence due to excision of lox $P$-flanked red $\mathrm{mT}$ through acinar-specific Cre recombinase, whereas GCDs and other non-acinar cells were mostly marked with red fluorescence in the control gland (Figure 3a, Ctrl). Both the size and number of green fluorescent-marked acinar cells in duct-ligated SMGs of $\mathrm{mT} / \mathrm{mG}$;Aqp5-Cre mice were notably reduced at day 3 post ligation (Figure 3a). Additionally, AQP5 IHC staining revealed reduced number of AQP5-positive acinar cells in L3 
a

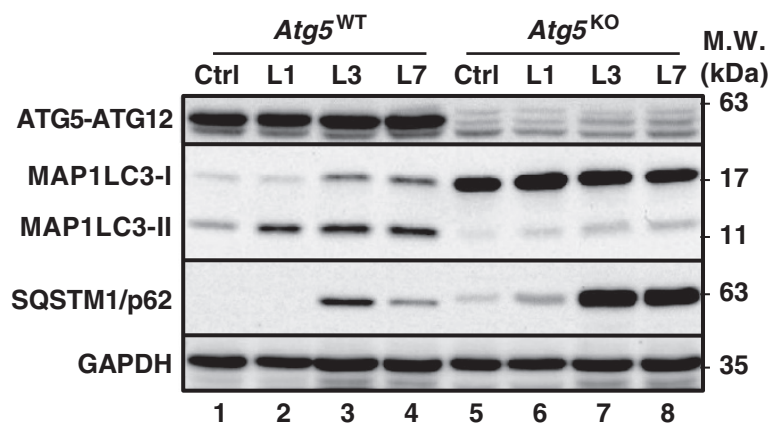

C
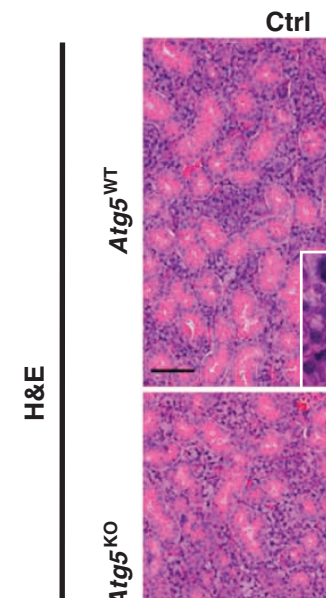

Ctrl

L1

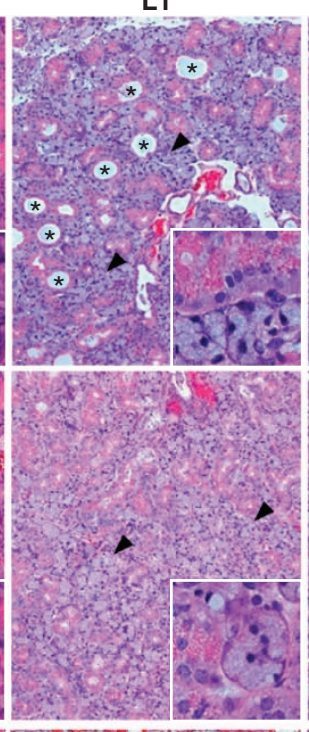

d

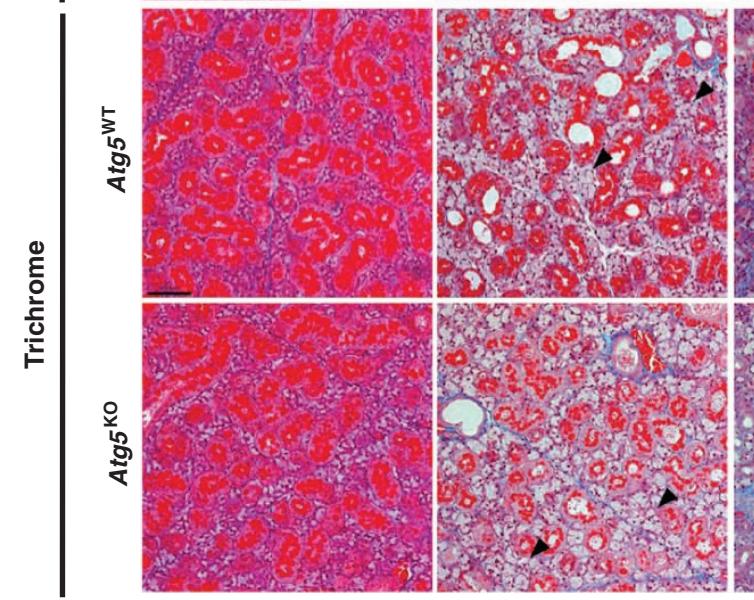

b

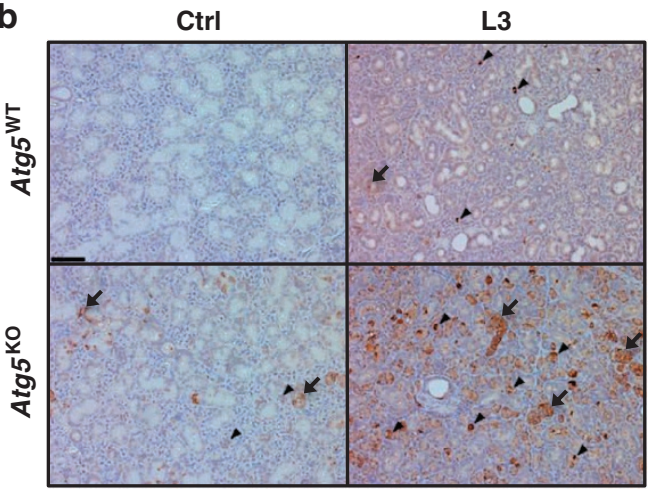

L3
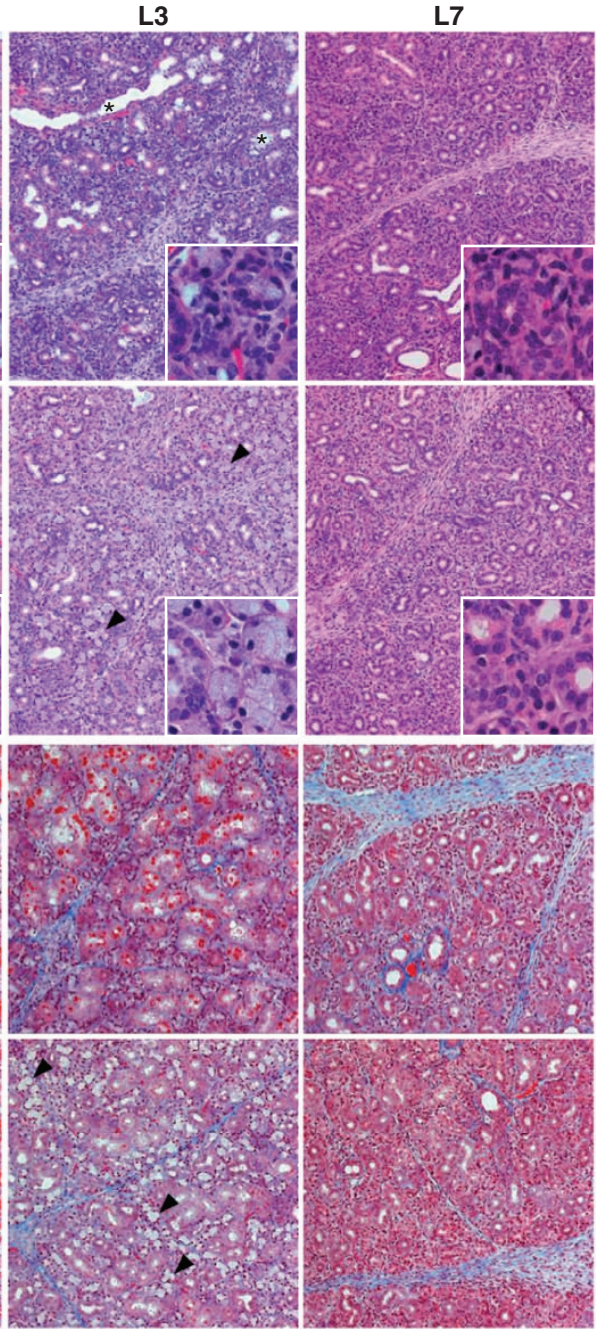

Figure 2 Duct ligation-induced autophagy affects morphological manifestations in post-ligated SMGs. (a) Analyses of autophagy-related proteins in post-ligated SMGs from $A \operatorname{tg} 5^{W T}$ and $A \operatorname{tg} 5^{K o}$ mice. Main excretory ducts from right SMG of individual mouse were ligated for 0 day (control; Ctrl), 1 day (L1), 3 days (L3) or 7 days (L7) before tissue harvesting. Equal amounts of whole gland homogenates were analyzed by western blot using the indicated primary antibodies. One representative western blot is shown $(N=3)$. (b) Immunohistochemical analyses show intense staining of SQSTM1 in acinar cells (arrowhead) of L3 SMGs from Atg $5^{K 0}$ mice. p62 accumulation was scattered in duct cells (arrow) of ligated glands of $A \operatorname{tg} 5^{\mathrm{WT}}$ and control SMGs of $A \operatorname{tg} 5^{\kappa 0}$ mice, and became prevalent in both acinar and duct cells of post-ligated L3 SMGs from Atg ${ }^{\mathrm{K}} \mathrm{mice}$. Bar: $100 \mu \mathrm{m}$. (c) Autophagy impinges on morphological changes induced by duct ligation. SMGs were dissected from $A \operatorname{tg} 5^{\mathrm{WT}}$ and $A \operatorname{tg} 5^{\kappa 0}$ mice at day 0 , day 1 , day 3 and day 7 post ligation. Duct obstruction led to gradually reduced eosinophilic secretory granules (bright pink) from GCDs in SMGs of both genotypes, and GCDs were severely dilated (asterisk), especially in L1 SMGs of Atg $5^{\text {WT }}$ mice. Acinar cells appeared enlarged in L1 SMGs of both genotypes. The enlarged acinar cells persisted in L3 SMGs of Atg $5^{k 0}$ (arrowhead), but not Atg $5^{\text {WT }}$ mice, and very few morphologically typical acinar cells were seen in L7 SMGs of both genotypes. Ctrl: non-operated control SMG. Magnification: $\times 100$, and enlarged view (inset): $\times 400$. Bar: $100 \mu \mathrm{m}$. (d) Progression of tissue fibrosis in post-ligated SMGs. FFPE SMG sections were stained with Trichrome. Excess fibrous connective tissues (blue) were present in L3 and L7 SMGs of $A \operatorname{tg} 5^{\mathrm{WT}}$ and Atg $5^{\mathrm{KO}}$ mice. Note the lack of eosinophilic cytoplasmic staining, likely reflecting mucin-like glycoprotein products, in enlarged acinar cells (arrowhead) from L1 glands of both genotypes, and from L3 SMGs of $\operatorname{Atg}^{\mathrm{K} 0}$ mice only. Bar: $100 \mu \mathrm{m}$ 


$$
\text { | }
$$

RFP

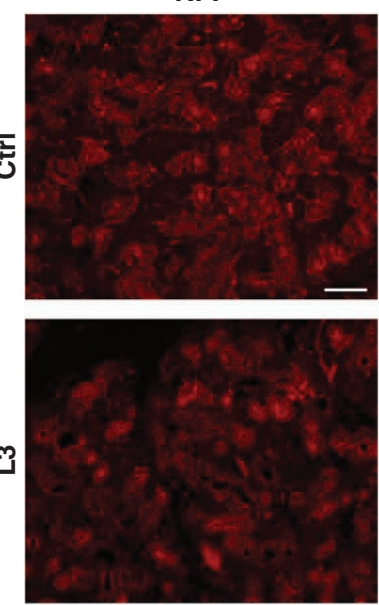

GFP
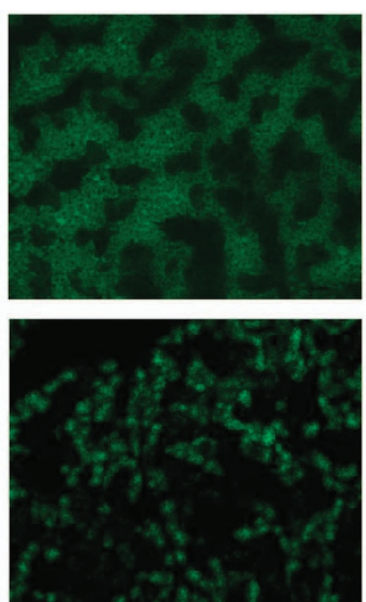
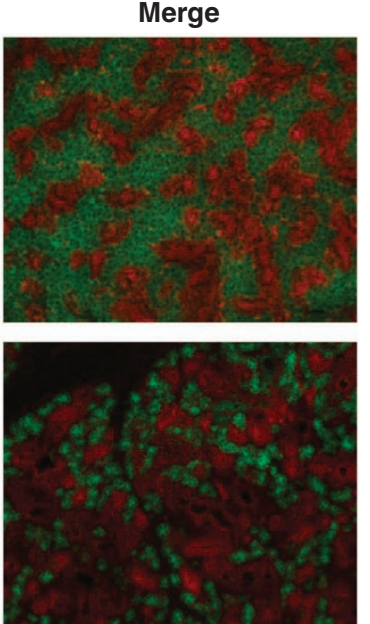

$\operatorname{Atg} 5^{\mathrm{KO}}$
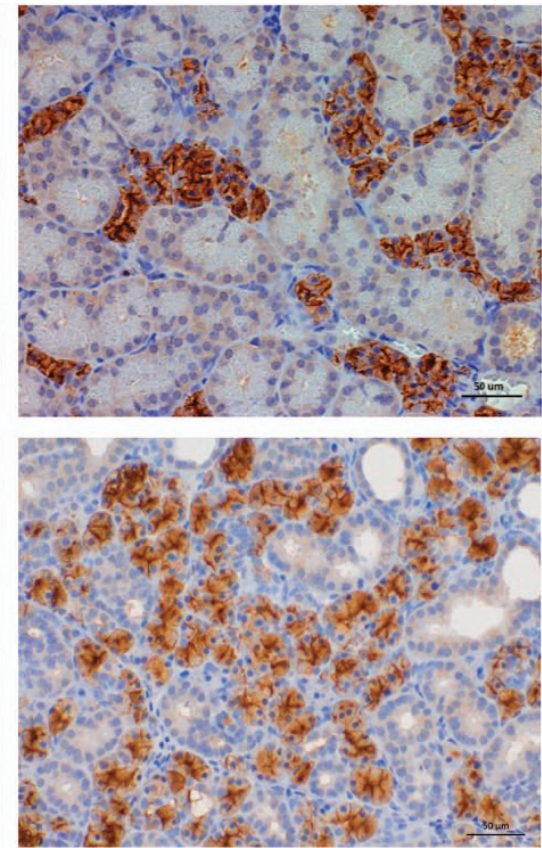

Figure 3 ATG5 exacerbates duct ligation-induced acinar cell atrophy. (a) Duct ligation induces acinar cell atrophy. Frozen sections of L3 SMGs and their contralateral counterparts (Ctrl) from $\mathrm{mT} / \mathrm{mG}$;Aqp5-Cre mice were visualized with fluorescence microscopy. Red fluorescence protein (RFP) was detected ubiquitously in all cells of $\mathrm{mT} / \mathrm{mG}$ mice except for Aqp5 promoter-driven Cre-expressing acinar cells, which were marked by green fluorescence protein (GFP). Number of GFP-labeled acinar cells was considerably less in L3 gland than control gland. Bar: $100 \mu \mathrm{m}$. (b) Suppression of ligation-induced acinar cell death in Atg $5^{\kappa 0}$ mice. L3 FFPE SMG sections from Atg $5^{\mathrm{WT}}$ and Atg ${ }^{\mathrm{K}}{ }^{\circ}$ mice were immunostained for acinar-specific AQP5 protein. Number of AQP5-stained acinar cells was considerably less in L3 SMGs of $A \operatorname{tg} 5^{\mathrm{NT}}$ than that of $A \operatorname{tg} 5^{{ }^{K 0}}$ mice. Bar: $50 \mu \mathrm{m}$

SMGs of $A \operatorname{tg} 5^{\mathrm{wT}}$ mice compared with L3 SMGs of $A \operatorname{tg} 5^{\mathrm{Ko}}$ mice (Figure 3b).

ATG5 KO delays ligation-induced apoptosis in SMG acinar cells. We next evaluated the functional role of enhanced autophagy in ligation-induced cell death. In situ apoptosis assays revealed that the percentage of ApopTagpositive cells in duct-ligated SMGs of $A \operatorname{tg} 5^{\mathrm{WT}}$ mice markedly increased at day 1 to day 3 , and then decreased at day 7 (Figure 4a). Conversely, the percentage of ApopTag-positive cells peaked at day 3 and day 7 after ligation in $A \operatorname{tg} 5^{\mathrm{KO}}$ mice (Figure 4a). Notably, most ApopTag-positive cells were localized outside the ductal system (Figure 4a). In agreement with in situ apoptosis data, caspase-3 activation was comparable between L3 and L7 SMGs, whereas cleaved caspase-3 levels markedly increased between L1 and L3 SMGs (Figure 4b,Supplementary Figure S5A). In addition, the message abundances of both death executor caspase-3 (Casp3) and apoptotic mediators Bcl2/11/Bim and Bmf were significantly upregulated following duct ligation and fold induction of Bmf, compared with control, were higher in $\operatorname{Atg}^{\mathrm{WT}}$ than in $\operatorname{Atg}^{\mathrm{K}}{ }^{\mathrm{O}}$ mice after 1 day of ligation (Supplementary Figure S2). A decrease in the abundance of acinar cell proline rich, lacrimal 1/mucin-10 (Prol1/Muc-10) 
message (Figure 4c), but not MUC-10 protein (Figure 4b, Supplementary Figure S5B), was detected in SMGs from $A \operatorname{tg} 5^{\mathrm{WT}}$ at day 3 and day 7 after duct ligation. In contrast, the abundance of ductal marker kallikrein 1 (KIk1) message was comparable between the two genotypes, except that it significantly increased by approximately 3-fold over the control level in L7 SMGs of Atg5 ${ }^{\mathrm{WT}}$ mice only (Figure 4c). Notably, the KLK1 protein abundance was higher in SMGs from $\operatorname{Atg} 5^{\mathrm{WT}}$ than that of $\operatorname{Atg} 5^{\kappa \mathrm{O}}$ at day 1 and day 3 after duct ligation (Figure 4b,Supplementary Figure S5C). Since duct a

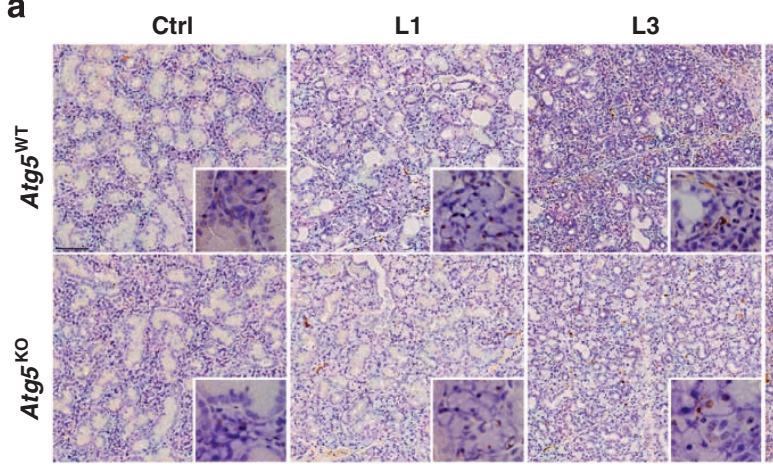

b

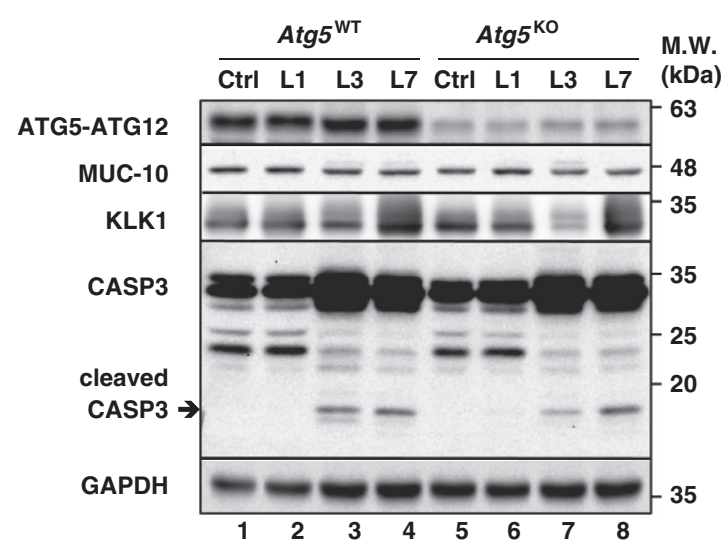

d

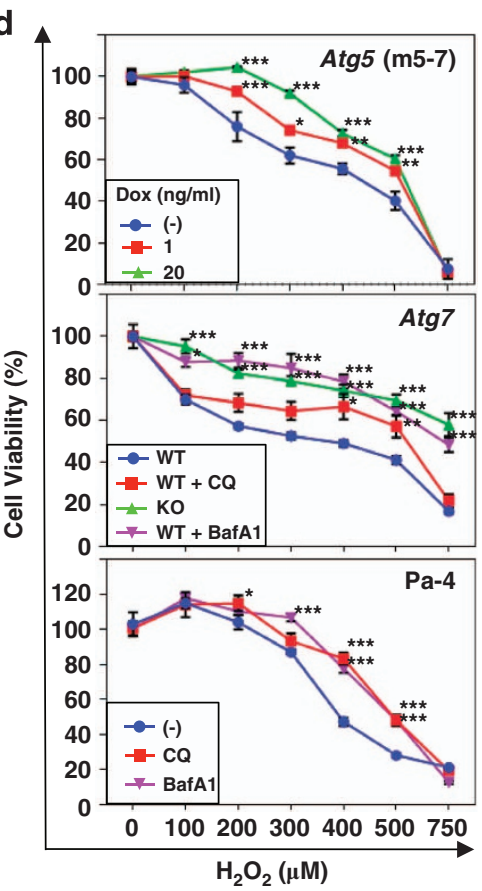

L7
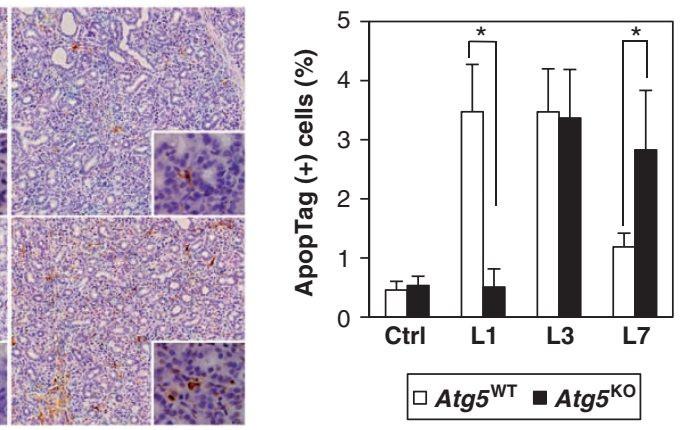

C
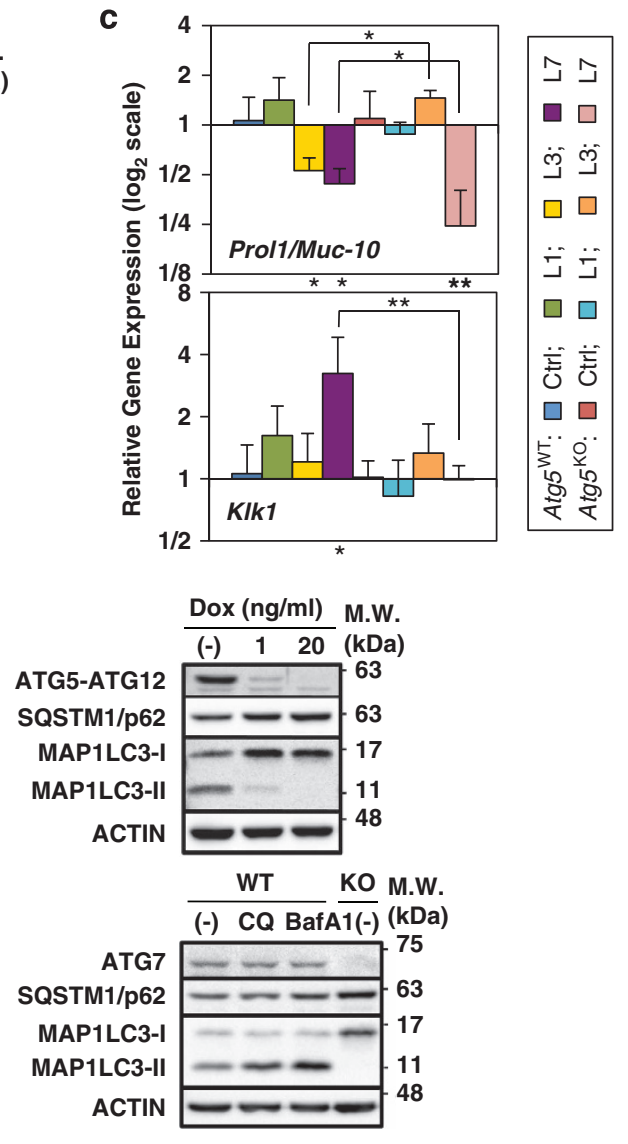

M.W.

(-) CQ BafA1 (kDa)

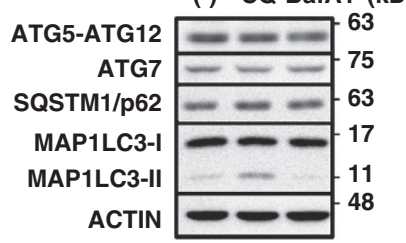


cells contribute to the regeneration of damaged exocrine glands, ${ }^{19,20}$ the increased KLK1 messages in L7 SMGs of $\operatorname{Atg}^{\mathrm{NT}}$ mice may reflect the initiation of regeneration. ${ }^{21}$

To validate the participation of ATG5 in cellular injury, $\mathrm{H}_{2} \mathrm{O}_{2}-$ induced cell death was examined in Atg5 Tet-Off MEF m5-7 cells $^{22}$ as an in vitro model. ATG5 levels in m5-7 cells were regulated by concentration of doxycycline (Dox; Figure 4d) in culture medium. The decreased ATG5 level clearly compromised cellular autophagic capacity, evident by decreased MAP1LC3-II and increased p62 levels. Notably, an inverse ATG5-dose-dependent correlation was observed between ATG5 protein levels and cell viabilities upon $\mathrm{H}_{2} \mathrm{O}_{2}$ treatment (Figure 4d). In addition to Atg5-KO cell model, we also tested sensitivity to $\mathrm{H}_{2} \mathrm{O}_{2}$-induced cell death affected by autophagy inhibition through Atg7-KO and autophagy inhibitors, chloroquine and bafilomycin A1 (BafA1), respectively, in Atg7-KO MEF and salivary $\mathrm{Pa}-4$ cells. Both autophagy-compromised MEFs and salivary $\mathrm{Pa}-4$ cells demonstrated reduced susceptibility to $\mathrm{H}_{2} \mathrm{O}_{2}$-induced cell death (Figure $4 \mathrm{~d}$ ). Taken together, we surmised that autophagy deficiency renders delayed cell death and/or greater apoptotic threshold upon stress.

Decreased ATG5 primes SMG duct cells for duct ligationinduced senescent phenotypes. Many upregulated proinflammatory mediator messages in ligated SMGs (Supplementary Figure S2) are also genes encoding SASP factors that are secreted by various cells undergoing premature senescence. ${ }^{23}$ Therefore, we asked whether duct ligation induced cellular senescence. SA- $\beta$-gal activity, which is strongly associated with senescent cells, ${ }^{24}$ was examined in control and ligated SMGs. While SMG SA- $\beta$-gal activity was detected sparingly at day 1 following duct ligation, SMGs from both $\operatorname{Atg} 5^{\mathrm{NT}}$ and $\operatorname{Atg}^{\mathrm{KO}}$ mice showed robust SA- $\beta$-gal staining after 3 days of ligation (Figure $5 a, L 3$ ). Notably, SA- $\beta$ gal activity was mainly detected in duct cells of GCDs of both genotypes. In addition, SA- $\beta$-gal activity was detected in limited duct cells of control SMGs from $\operatorname{Atg} 5^{\kappa \circ}$ mice, but not $A \operatorname{tg} 5^{\mathrm{NT}}$ mice. After 7 days of ligation, the SA- $\beta$-gal staining remained intense in the duct cells of post-ligated SMGs of Atg5 ${ }^{\mathrm{KO}}$ mice, but markedly decreased in the corresponding counterparts of $A \operatorname{tg} 5^{\mathrm{WT}}$ mice (Figure 5a, L7). We postulated that the attenuated autophagy resulting from reduced ATG5 abundance in SMG duct cells of $\operatorname{Atg} 5^{\mathrm{KO}}$ mice (Figure 1b) attributes to the lingering SA- $\beta$-gal activity from day 3 to day 7 in $\mathrm{KO}$ mice.
To corroborate the results of SA- $\beta$-gal accumulation, we confirmed that other senescence markers, including cell-cycle inhibitors Cdkn2a/p16Ink4a, Cdkn2a/p19Arf, Cdkn2b/p15 and $C d k n 1 a / p 21,{ }^{25}$ were upregulated following duct ligation (Supplementary Figure S2). CDKN1A/p21 IHC analyses showed prominent CDKN1A/p21 staining in GCDs of L3 SMGs (Figure $5 \mathrm{~b}$ ), independently validating duct ligationinduced senescent phenotype in duct cells of ligated SMGs. In that, CDKN1A/p21 signal was stronger at day 1 post ligation in Atg $5^{\mathrm{KO}}$ mice than in $\operatorname{Atg}^{\mathrm{WT}}$ mice. Consistent with SA- $\beta$-gal activity (Figure $5 a$ ), the majority of GCDs in SMGs of $A \operatorname{tg} 5^{\mathrm{Ko}}$ mice at day 7 post ligation stained positive for CDKN1A/p21, but much less so in L7 SMGs of $\operatorname{Atg}^{\mathrm{NT}}$ mice (Figure 5b, Supplementary Figure S6).

We then used a cell-based assay to confirm the role of ATG5 in premature senescence by examining $\mathrm{H}_{2} \mathrm{O}_{2}$-induced senescent phenotype in Atg5 Tet-Off MEF m5-7 and Atg5-KO MEF cells. ${ }^{22}$ Treatment with sublethal concentrations of $\mathrm{H}_{2} \mathrm{O}_{2}$ resulted in more SA- $\beta$-gal-positive Atg5-KO MEF cells than in WT MEF cells (Figure $5 \mathrm{c}$ ). In addition, steady-state abundance of $\mathrm{CDKN} 1 \mathrm{~A} / \mathrm{p} 21$ protein was substantially increased by sublethal concentrations of $\mathrm{H}_{2} \mathrm{O}_{2}$ treatment in Atg5-KO MEF cells (Figure $5 \mathrm{~d}$ ). Time course analysis revealed that p21 level peaked in KO but not in WT cells, 1 day after $\mathrm{H}_{2} \mathrm{O}_{2}$ treatment, while p38 was activated immediate (2 h) after the treatment in both cells (Figure $5 \mathrm{~d}$ ). In addition, there is a positive correlation between protein levels of p21 and p62 accumulation (Figure $5 \mathrm{~d}$ ).

Macrophage activation during duct ligation. Compare with $\operatorname{Atg} 5^{\mathrm{WT}}$ mice, duct ligation induced sustained senescent phenotypes in SMG duct cells (Figures $5 a$ and b) and delayed apoptosis in acinar cells (Figures 3 and 4) of $\operatorname{Atg}^{\mathrm{KO}}$ mice. Macrophages are key components in tissue repair and remodeling during wound healing. To determine whether distinct programs for clearance of damaged cells may have arisen based on cellular autophagy proficiency, we examined recruitment of macrophages following duct ligation. IHC staining for F4/80 revealed that tissue injury induced by duct ligation was accompanied by macrophage recruitment throughout the progression of the tissue injury (Supplementary Figure S7). Notably, F4/80-positive macrophages massively accumulated in injured SMGs at day 3 and day 7 after ligation, however, indistinguishable between WT and $\mathrm{KO}$ mice. In addition, expression level of the

Figure 4 Acinar cell apoptosis is delayed in post-ligated SMGs of ATG5-deficient mice. (a) ATG5 status impinges upon duct ligation-triggered acinar apoptosis. Apoptosis by ApopTag Peroxidase (brown nuclear staining) was visualized using an In situ Apoptosis Detection Kit (left panel). Peak apoptosis was detected in L1 and L3 SMGs of Atg $5^{\mathrm{WT}}$ mice, whereas the strongest ApopTag signals were detected in L3 and L7 SMGs of Atg ${ }^{{ }^{\circ}}$ mice. Magnification: × 100, and enlarged view (inset): $\times 400$. Bar: $100 \mu \mathrm{m}$. Percent ApopTagpositive cells quantified by dividing the total ApopTag-positive cells by total number of cells examined from 10 randomly chosen fields are shown (right panel). Student's $t$-test was employed to determine statistically significant differences in percentage of ApopTag-positive cells between $A \operatorname{tg} 5^{\mathrm{WT}}$ and $\operatorname{Atg} 5^{K 0}$ groups. Results are shown as mean \pm S.D.; ${ }^{*} P<0.05$. (b) ATG5 deficiency delays caspase-3 activation. Equal amounts of whole SMG lysates from Ctrl, L1, L3 and L7 SMGs of Atg5 ${ }^{\text {WT }}$ and Atg $5^{\kappa /}$ mice were analyzed on western blots using indicated antibodies. The cleavage of caspase-3 represents caspase-3 activation. (c) Gene expression analyses of Prol1/Muc-10 and Klk1, markers for acinar and duct cells, respectively. SMG duct ligation was performed as described in Figure 2. Expression of the indicated messages in ligated and control SMGs was analyzed by quantitative RT-PCR analyses. Relative gene expression was calculated where respective mean value for control SMG set to 1 for each amplification ( $N \geq 4$ ). Non-parametric Mann-Whitney test was performed to compare expression levels between respective ligated and control SMGs $(* ;$ below bars), and between same-day ligated SMGs and control SMGs from $A \operatorname{tg} 5^{\text {wT }}$ and $A \operatorname{tg} 5^{{ }^{\circ}}$ (*; above bars). Results are shown as mean \pm S.D.; ${ }^{*} P<0.05$; ${ }^{* *} P<0.01$. (d) Autophagy inhibition correlates with resistance to $\mathrm{H}_{2} \mathrm{O}_{2}$-induced cell death. Cell viability was measured in m5-7, Atg7-KO MEF, WT MEF and salivary Pa-4 cells treated with indicated concentrations of $\mathrm{H}_{2} \mathrm{O}_{2}$ in combination with chloroquine (CQ; $20 \mu \mathrm{M}$ ) or baflomycin A1 (BafA1; $10 \mathrm{nM}$ ) for $48 \mathrm{~h}$ and compared with that of the control cells. Data were analyzed with ANOVA followed by Bonferroni $t$-test to determine the statistical differences between treatment and control group (left panels). Representative western blots (right panels), in which total lysates from cells treated for $6 \mathrm{~h}$ with vehicle, $\mathrm{CQ}(20 \mu \mathrm{M})$ or BafA1 $(10 \mathrm{nM})$ were stained with indicated antibodies, are shown. Results are shown as mean \pm S.E.M.; $N=3 ;{ }^{*} P<0.05 ;{ }^{* *} P<0.01 ;{ }^{* * \star} P<0.001$ 
a

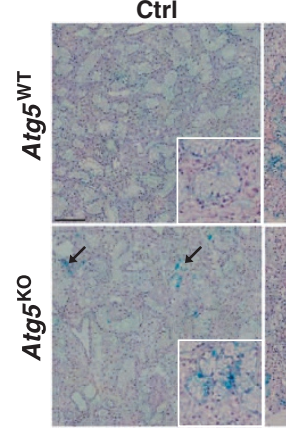

b

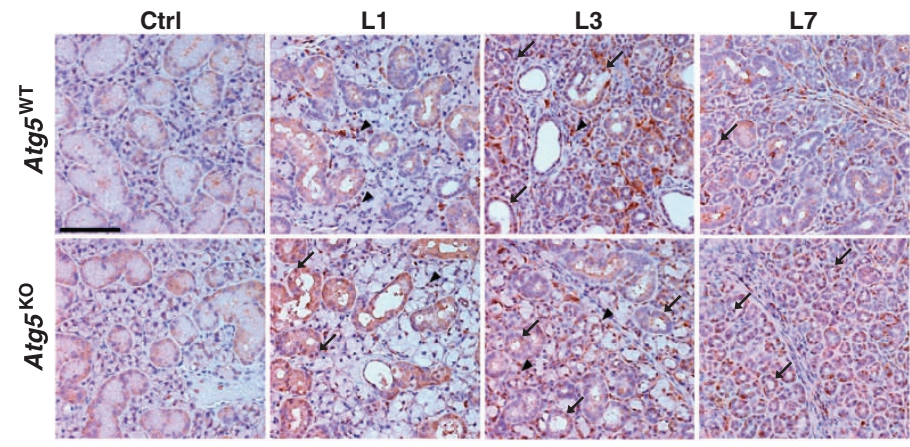

C
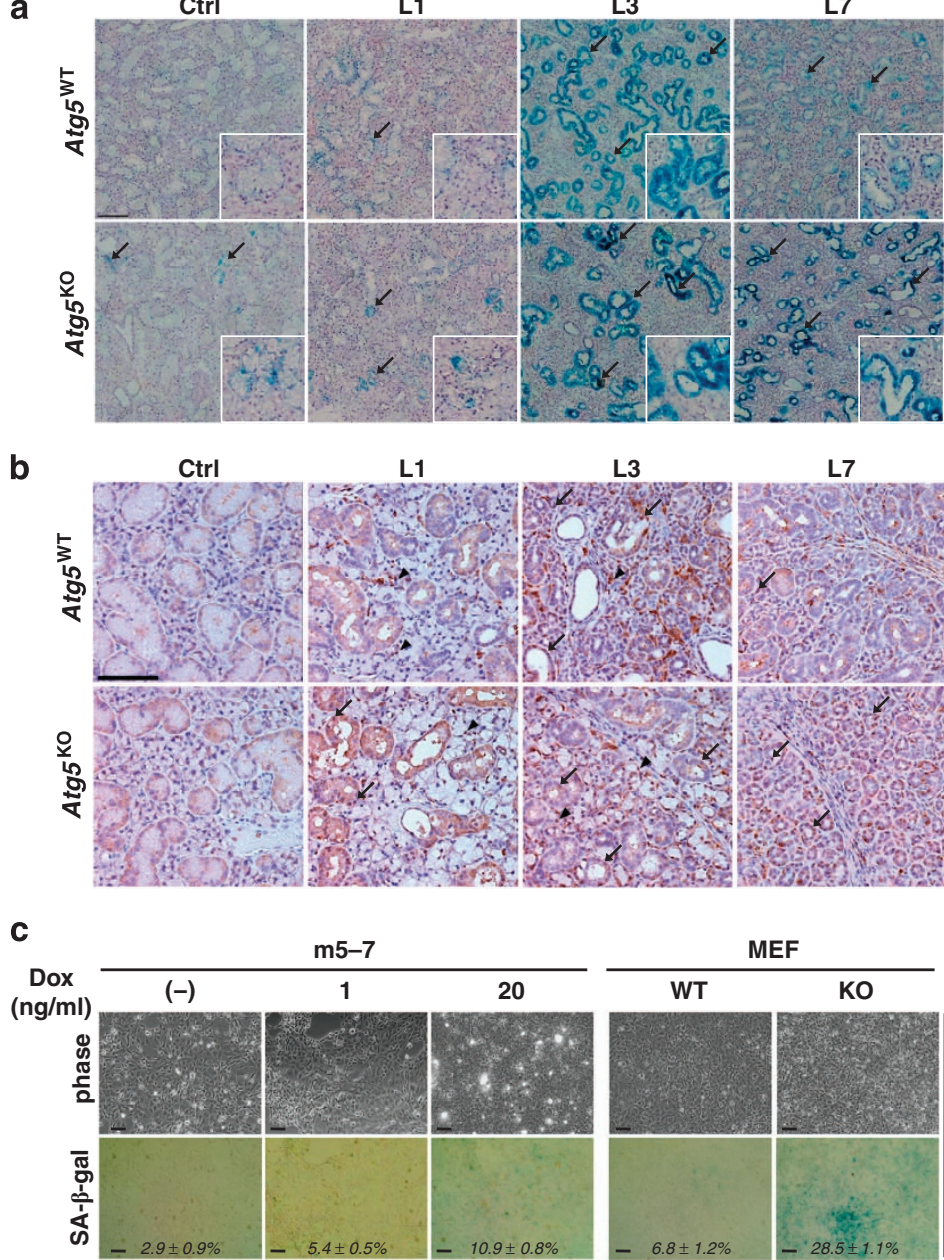

L7
L3

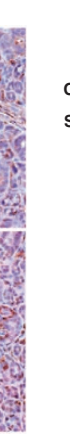

d

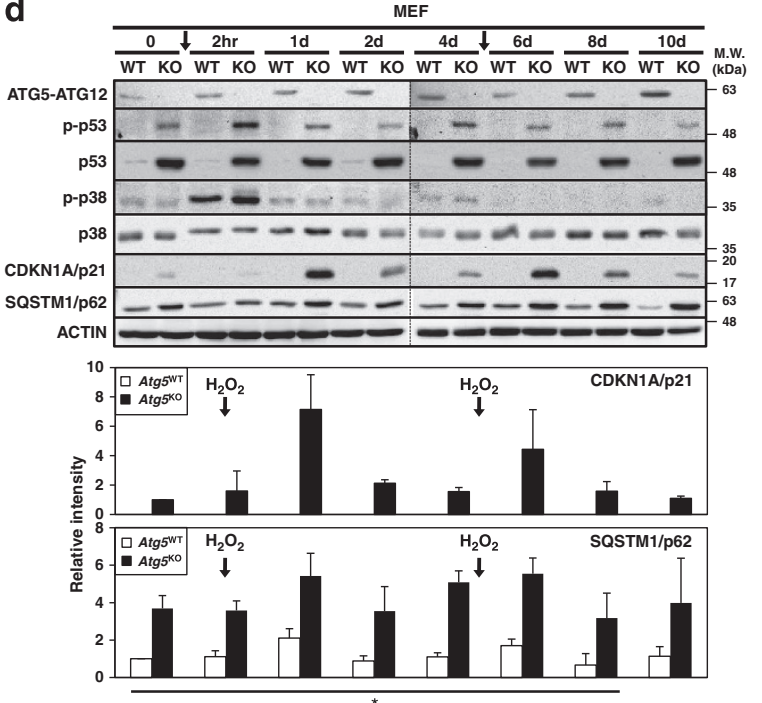

Figure 5 Duct ligation induces sustained premature cellular senescence phenotypes in ATG5-deficient duct cells. (a) ATG5 deficiency predisposes and results in persistent stress-induced SA- $\beta$-gal activity in duct cells. Frozen sections of pre-ligated SMGs (Ctrl) of $A$ tg $5^{\text {Ko }}$ mice were positive, albeit weak, for SA- $\beta$-gal activities (indicated by arrows). Duct ligation intensified SA- $\beta$-gal activities, which peaked in L3 SMGs from both genotypes. Of note, SA- $\beta$-gal signals remained strong in L7 SMGs from Atg $5^{k 0}$ mice while diminished in L7 SMGs from Atg5 ${ }^{W T}$ mice. Magnification: $\times 100$, and enlarged view (inset): 200X. Bar: $100 \mu \mathrm{m}$. (b) Increased steady-state protein level of senescence marker CDKN1A/p21 in post-ligated glands. FFPE SMG sections were immunostained with an anti-CDKN1A/p21 antibody. Nuclear and cytoplasmic CDKN1A/p21 signals were detected mostly in GCDs (arrow) and some acinar cells (arrowhead) of post-ligated SMGs. Magnification: 200X. Bar: $100 \mu \mathrm{m}$. (c and d) ATG5 level modulates sublethal $\mathrm{H}_{2} \mathrm{O}_{2}$-induced senescent phenotypes in MEF cells. The Atg5 Tet-Off MEF m5-7 cells, Atg $5^{-1-}$ MEF (KO), and wild-type MEF (WT) cells were treated twice at day 0 and day 5 with $\mathrm{H}_{2} \mathrm{O}_{2}$ as described in Materials and Methods, and assayed for SA- $\beta$-gal activity (c) or lysed at different time points and subjected to western analyses with indicated antibodies (d). ATG5 expression in Atg5 Tet-Off MEF m5-7 cell was suppressed by doxycycline (Dox) supplementation, as in Figure 4. Percentages of SA- $\beta$-gal-positive cells over total number of cells are indicated (italic). Treatment with sublethal concentrations of $\mathrm{H}_{2} \mathrm{O}_{2}$ elicited more SA- $\beta$-gal-positive ATG5-KO MEFs than WT MEFs (c). $\mathrm{H}_{2} \mathrm{O}_{2}$ transiently induces p21 in KO MEFs after 1 day of $\mathrm{H}_{2} \mathrm{O}_{2}$ treatment (day 0 and day 5, arrows) (top panel) and the quantitative analysis of corresponding p21 and p62 in this representative western is shown below by setting respective p21 protein level of untreated KO MEF ad p62 protein level of untreated WT MEF at one, respectively (lower panel) (d). Results are shown as mean \pm S.D.; $N=3 ;{ }^{*} P<0.05$ (for p62 between two genotypes). Bar: $100 \mu \mathrm{m}$

chemoattractant chemokine chemokine (C-C motif) ligand 2/monocyte chemoattractant protein-1 (CC/2/MCP-1), which was highly induced in SMGs following ligation (Supplementary Figure S2), was also comparable between the two genotypes. We concluded that levels of ATG5 did not affect macrophage activation in the duct ligation model.

\section{Discussion}

It is now generally recognized that autophagic process has a pivotal role in cellular homeostasis and tissue adaptive responses to stress and injury. Herein, we used an injury model of SMG duct obstruction and conditional Atg5 KO to explore the simultaneous interplay among autophagy, inflammation, stress-induced premature senescence and apoptosis in vivo. Ligation of excretory duct of exocrine glands, such as $\mathrm{SMG}^{26}$ and pancreas, ${ }^{27}$ induces acinar cell injury and death as well as ductal cell proliferation when the passage of secretions is blocked. However, the mechanism dictating the fate of individual cell types, in response to stress, within the same tissue is still unclear. Our report represents the first of its kind using conditional ATG5-KO mice to delineate molecular mechanism of duct cell survival and acinar cell death in atrophied SMGs following duct ligation in vivo. One major finding of this study is that combined effect from reduced ATG5 abundance and disruption of SMG duct ligation-induced 
autophagy causes a phenotype of delayed apoptosis in acinar cells and sustained premature senescence in duct cells of post-ligated SMGs from $\operatorname{Atg}^{\mathrm{K}}{ }^{\circ}$ mice (Figure 6).

Conceivably, depending on stress intensity, autophagy could regulate cell death pathway with two distinct outcomes: (1) the induction of autophagy in responses to ductal obstruction may be initially beneficial for ligated SMGs by eliminating superfluous proteins accumulated within acinar cells due to blocked secretory outflow. This will allow cells to adapt to the hostile conditions. (2) The sustained autophagy may exacerbate stress condition and induce autophagic cell death (or 'autosis') accompanied by ER dilation and nuclear convolution. ${ }^{28}$ Alternatively, autophagosomes could serve as platforms for caspase activation, ${ }^{29}$ degrading anti-apoptotic factors, ${ }^{30}$ and crosstalking with cell killing mechanisms such as p53 and JNK pathways. ${ }^{31}$ Here we showed that acinar cells in post-ligated SMGs underwent programmed cell death after prolonged ligation. Although apoptosis occurred regardless of autophagy status, apoptotic cell death was delayed in ATG5deficient acinar cells, compared with autophagy-competent cells (Figures 3 and 4a). Furthermore, autophagy-impaired cells were more resistant to $\mathrm{H}_{2} \mathrm{O}_{2}$-induce cell lethality (Figure 4d), supporting our notion. ATG5, although an essential protein in autophagosome formation, has additional functions beyond autophagy. For instance, both ATG5dependent mitotic catastrophe ${ }^{32}$ and cell death ${ }^{33}$ in cells treated with cytotoxic agents have recently been reported. More importantly, calpain-cleaved ATG5 is known to activate caspases to enhance susceptibility toward apoptotic stimuli, thus ATG5 functions as a molecular link between autophagy and apoptosis. $^{34}$ Conceivably, the absence of ATG5dependent caspase activation could account for the initially delayed apoptosis in day-1 post-ligated SMGs of the $\operatorname{Atg} 5^{\mathrm{KO}}$ mice. Thus, the delayed Atg5-KO acinar cell death could be either autophagy dependent or ATG5 dependent or their combination.

Senescence is a state of stable cell-cycle arrest. ${ }^{35,36}$ Accumulating evidence from several in vivo senescent mouse models have suggested that the early onset of senescent

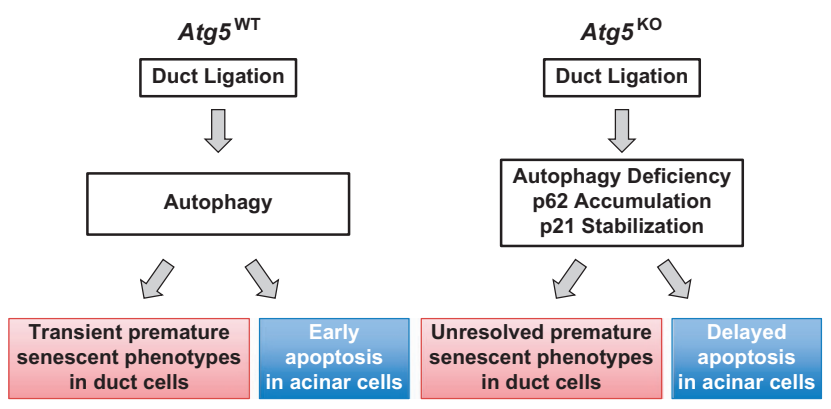

Figure 6 Model for role of ATG5 in ligation-induced apoptosis and premature senescent phenotypes. Duct ligation induces autophagy, acinar cell death through apoptosis, and transient senescent phenotypes in duct cells of SMGs from WT mice. ATG5 deficiency disturbed homeostasis in tissue responses to obstruction stressor stemming from duct ligation, rendering sustained senescent phenotypes in duct cells and delayed apoptotic cell death in acinar cells. The lack of contribution of cleaved ATG5 to apoptosis ${ }^{34}$ could account for the delayed acinar cell death in duct-ligated SMGs of KO mice. On the other hand, sustained senescent phenotypes in duct cells may be due to stabilization of p21 through sequestration by excess polyubiquitinbinding protein p62 in duct-ligated KO mice phenotypes results from the expression, activation or deletion of genes involved in cell-cycle progression. ${ }^{37-41}$ Controversy over the relationship between autophagy and senescence exists because both a direct relationship and an inverse relationship were reported. ${ }^{42}$ In agreement with inverse relationships, ${ }^{9,43}$ the emergence of unstressed $S A-\beta$-gal activity in duct cells of SMGs was only detected from young (6-8 weeks old) $\operatorname{Atg} 5^{\kappa \circ}$, but not from $\operatorname{Atg} 5^{\mathrm{wT}}$, mice (Figure 5a, Ctrl). Moreover, stress-induced senescent phenotypes were activated transiently in duct cells of post-ligated SMGs from Atg $5^{\mathrm{WT}}$ mice, however, persisted through day 7 in $A \operatorname{tg} 5^{\mathrm{KO}}$ mice (Figures $5 \mathrm{a}$ and b). We hypothesize that senescent phenotypes were transient in duct-ligated SMGs from Atg $^{\mathrm{WT}}$ mice because autophagy removes superfluous proteins resulted from blunted secretion, thus maintains cellular homeostasis. When the clearance mechanism is impaired, damaged organelles and other proteins accumulate, leading to unresolved stress phenotypes in the autophagy-impaired SMGs. These observations of increased p21 protein level and intensified SA- $\beta$-gal signals in sublethal $\mathrm{H}_{2} \mathrm{O}_{2}$-treated Atg5compromised MEF cells than the corresponding WT MEF cells (Figures $5 c$ and d) supported the notion that lower ATG5 abundance in duct cells of $A \operatorname{tg} 5^{K \mathrm{O}}$ mice, compared with $A \operatorname{tg} 5^{\mathrm{NT}}$ mice (Figure 1b), primed these SMG duct cells susceptibility to persistent senescent-associated phenotypes (Figure 5a).

Extended outflow blockage led to extensive accumulation of p62 protein in SMGs of KO mice (Figures $2 a$ and b). The polyubiquitin-binding protein p62, through interaction with LC3, is involved in delivering cargoes to the autophagy machinery or lysosomes for degradation. ${ }^{44}$ In autophagydeficient Atg5-KO cells, excessive p62, instead, sequesters ubiquitinated proteins from proteasomal degradation, extending their half-life. ${ }^{45}$ Conceivably, p21, a short-lived protein, could therefore prevail in day-7 post-ligated SMGs of $A \operatorname{tg} 5^{\kappa \circ}$ mice through reduced turnover (Figure 5b). However, we cannot rule out the possibility that the stressed acinar cells might modulate the fate of duct cells in a paracrine and autophagy-dependent manner. Even though cellular senescence is generally considered as irreversible, escape scenarios, such as p53 pathway inactivation, exist to allow cells to re-enter the cell cycle. ${ }^{13,46}$ Duct ligation clearly leads to a transient senescent phenotype in post-ligated duct cells of $\operatorname{Atg} 5^{\mathrm{WT}}$ but not $\operatorname{Atg} 5^{\mathrm{Ko}}$ mice. The exact underlying mechanism is still unclear. It is possible that autophagy keeps p62 levels in check, thus promotes resolution of senescent phenotype. Alternatively, autophagy could facilitate the removal of dead cells at the final stage of post-ligation period, minimizing the stress input from local environment.

Collectively, our results explicitly show that ATG5 deficiency primes SMG cells with increased expression of proinflammatory cytokine and Cdkn1a/p21 messages, and the lack of proper duct ligation-induced autophagy dysregulates the tempo and duration of sequential and overlapping elements of tissue injury, including inflammatory responses, stressinduced premature senescence and apoptosis. We therefore conclude that duct ligation-induced autophagy has a dynamic role in preserving the structural integrity of duct and acinar cells in duct-obstructed SMGs. One potentially important mechanism of regulating autophagy in post-ligated SMGs is through the mammalian target of rapamycin (mTOR). 
Bozorgi et al. ${ }^{14}$ have recently reported while that mTOR is switched off in normal salivary glands, it gets switched on during the course of duct ligation. As mTOR inhibition is instrumental for autophagy induction, ${ }^{1}$ the activation of mTORC1 appears to be sufficient to suppress autophagy by preventing the formation of ATG complex. ${ }^{47}$ One possible explanation to reconcile our data with theirs is that mTOR activation could represent a feedback mechanism to escape from autosis or autophagy-induced cell death. Nonetheless, these discordances underlie the complexity of in vivo role ATG5 or autophagy partakes in post-ligated SMGs and hint at their respective interactions with other stress-triggered signaling pathways.

\section{Materials and Methods \\ Generation of salivary acinar-specific Atg5-deficient mice. Mice with salivary acinar-specific ATG5 deficiency were generated by crossing Atg $5^{\text {floxfllox }}$ mice $\left(\operatorname{Atg}^{5 / / 5}\right)^{4}$ with Aqp5-Cre mice ${ }^{17}$ that express Cre recombinase under the control of the Aqp5 promoter. Atg $5^{t /-} ;$ Aqp5-Cre genotypes arose from breeding $\operatorname{Atg}^{f / f}$ with $A \operatorname{Atg} 5^{f / f} ; A q p 5$-Cre mice for several generations, most likely through promiscuous Cre recombinase activity during developmental processes, such as gametogenesis. ${ }^{48}$ These mice were selected for mating with C57BL/6 mice to generate the $\operatorname{Atg}^{+/-} ;$Aqp5-Cre mice used in this study. Crossing $A \operatorname{Atg} 5^{f / t}$ and

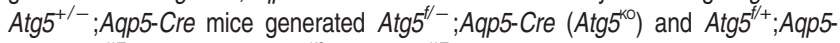 Cre $\left(A \operatorname{tg} 5^{\mathrm{WT}}\right)$ mice. Both $\operatorname{Atg}^{5^{\circ 0}}$ and $A \operatorname{tg} 5^{\mathrm{WT}}$ mice were on a mixed C57BL/6 and 129S6/SvEvTac background and appeared normal without gross abnormality. Genotypes was screened using the following PCR primer pairs: Atg5, forward, 5'-AAGCACCTAGTCACACCACATCCA-3', and reverse, 5'-CACGTGTGAGTGATG GTTGGCTTT-3' for simultaneously detecting the WT and floxed Atg5 alleles; $\triangle$ Atg5; forward, 5'-CAGGGAATGGTGTCTCCCAC-3', and reverse, 5'-GTACTGCA TAATGGTTTAACTCTTGC-3' to detect deleted the Atg5 allele; and Cre, forward, 5'-TGCCCAAGAAGAAGAGGAAGGTGT-3', and reverse, 5'-GCCGCATAACCAGT GAAACAGCAT-3'.}

Generation of reporter mice. Reporter $\mathrm{mT} / \mathrm{mG}$;Aqp5-Cre mice were generated by crossing $\mathrm{mT} / \mathrm{mG}^{49}$ and Aqp5-Cre mice. ${ }^{17}$

Cell line, $\mathrm{H}_{2} \mathrm{O}_{2}$ treatment and cell viability assay. WT, Atg5-KO and Atg7-KO MEF cells (kind gift from Dr. Chengyu Liang, USC) were cultured in DMEM with $10 \%$ FBS. Salivary Pa-4 cells were cultured as we described previously. ${ }^{50}$ The Atg5 Tet-Off MEF m5-7 cells ${ }^{22}$ were maintained in DMEM containing 10\% FBS with doxycycline (Dox, $20 \mathrm{ng} / \mathrm{ml}$ ) to fully suppress Atg5 expression, as we described previously. ${ }^{51}$ To restore Atg5 expression, cells were cultured either in Dox-free medium for full restoration or in medium with $1 \mathrm{ng} / \mathrm{ml}$ Dox for partial restoration. These cells were treated with up to $1 \mathrm{mM} \mathrm{H} \mathrm{H}_{2} \mathrm{O}_{2}$ alone or in the presence of chloroquine $(20 \mu \mathrm{M})$ or BafA1 $(10 \mathrm{nM})$ as indicated, and cell viability was assessed $48 \mathrm{~h}$ later based on acid phosphatase assay described by Yang et $a .^{52}$ In brief, cells in a 96-well plate were washed with PBS and incubated with $100 \mu \mathrm{l}$ p-nitrophenyl phosphate (Sigma-Aldrich, St. Louis, MO, USA; N4645) in $5 \mathrm{mM}$ in $0.1 \mathrm{M}$ sodium acetate and $0.1 \%$ Triton $\mathrm{X}-100, \mathrm{pH} 5.0$, for $1 \mathrm{~h}$ at $37^{\circ} \mathrm{C}$. The reaction was stopped with the addition of $\mathrm{NaOH}(10 \mu l, 1 \mathrm{~N})$ and absorbance measured at $405 \mathrm{~nm}$ using a microplate reader. For senescence induction, $\mathrm{m} 5-7$ cells were maintained in growth media containing different concentrations of doxycycline $(0,1 \mathrm{and} 20 \mathrm{ng} / \mathrm{ml})$. At day 1 after seeding, cells were treated with sublethal dose of $\mathrm{H}_{2} \mathrm{O}_{2}(75 \mu \mathrm{M})$ for $2 \mathrm{~h}$, washed and cultured in growth medium for 5 days. The $\mathrm{H}_{2} \mathrm{O}_{2}$ treatment and recovery were repeated once before cell harvesting. WT and Atg5-KO MEF cells were treated with $150 \mu \mathrm{M} \mathrm{H}_{2} \mathrm{O}_{2}$ using the same protocol as for m5-7 cells, and the cells were analyzed for $\mathrm{SA}-\beta$-gal activity as below.

Fluorescent microscopy. Fluorescent images of frozen sections from SMG of $\mathrm{mT} / \mathrm{mG}$;Aqp5-Cre mice were acquired using an Olympus AX70 microscope (Olympus, Tokyo, Japan). All images were compiled using Image-Pro (version 6.3, Media Cybernetics, Rockville, MD, USA).

Submandibular duct ligation. Due to gender dimorphism in mouse SMGs, ${ }^{53}$ male mice (6-8 weeks old) were used exclusively in all ligation studies reported here. Mice were maintained under 12-h light/dark cycles with unlimited access to food and water. Unilateral ligation of the main excretory ducts of right SMGs, for a period from 1 to 7 days, was performed using surgical sutures, according to Turner et $a l^{54}$ The contralateral left SMGs, which served as ligation controls, from the same mice were also harvested for comparison. Animals were euthanized at indicated times following ligation. Both control and ligated SMGs were removed and either snap-frozen in liquid nitrogen for western and real-time RT-PCR analyses or fixed in $4 \%$ paraformaldehyde for Hematoxylin and Eosin (H\&E) staining and IHC analyses. City of Hope Institutional Animal Care and Use Committee approved all surgical procedures reported here.

IHC analysis. IHC staining was performed on $5-\mu \mathrm{m}$ thick tissue sections prepared from formalin fixed, paraffin-embedded (FFPE) tissues. FFPE tissue sections were deparaffinized in xylene then hydrated through graded ethanol and distilled water. Samples were then quenched in $1 \%$ hydrogen peroxide and pretreated with steam from citrate buffer (Vector Laboratories, Burlingame, CA, USA; $\mathrm{H}-3300$ ) to promote antigen retrieval. After antigen retrieval, slides were incubated in Protein Block for $1 \mathrm{~h}$, then incubated with primary antibodies ATG5 (1: 800 dilution, RT, $1 \mathrm{~h}$; Novus Biologicals, Littleton, CO, USA; NB110-53818), SQSTM1/p62 (1:1500 dilution, $4^{\circ} \mathrm{C}$, overnight; Wako Chemicals, Richmond, VA, USA; 018-22141), AQP5 (1:150 dilution, RT, 30 min; Alomone Labs, Jerusalem, Israel; AQP-005), F4/80 (1:50 dilution, RT, $30 \mathrm{~min}$; AbD Serotec, Raleigh, NC, USA; MCA497R), or CDKN1 A/p21 (1:1000 dilution, $4^{\circ} \mathrm{C}$, overnight; Abcam, Cambridge, MA, USA; ab2961), respectively. For ATG5, SQSTM1 and CDKN1A/p21 IHCs, slides were then washed in PBS and incubated with biotinylated secondary antibody (1 : 200 dilution, RT, 30 min; Vector Labs, BA-1000) and VECTASTAIN Elite ABC protocol followed (Vector Laboratories, PK-6100). For AQP5 and F4/80 IHCs, slides were washed in Dako buffer after primary antibody incubation and incubated with EnVision+ (Dako, Carpinteria, CA, USA; K4010) secondary antibody for 30 min. After three more washes in Dako buffer, slides were incubated with chromogen $3,3^{\prime}$ diaminobenzidine tetrahydrochloride (DAB), counterstained with hematoxylin, and mounted.

Real-time reverse-transcription PCR. Total RNA was extracted from SMGs with TRIzol (Life Technologies, Grand Island, NY, USA), according to the manufacturer's instructions. Synthesis of CDNA was performed using the iScript cDNA Synthesis Kit (Bio-Rad, Hercules, CA, USA; 170-8891). The cDNA was amplified using IQ SYBR Green Supermix and specific primer pairs in a My IQ RealTime PCR Detection System (Bio-Rad, 170-8882). Relative mRNA expression levels were calculated using the $\Delta \mathrm{C}_{\mathrm{t}}$ method, as previously described, ${ }^{50}$ against $\mathrm{Gclc}$, a message that we found stable throughout the duct ligation process. The primer pairs used are shown in Supplementary Table S1.

Western analyses. Whole tissue lysates were prepared using the Qproteome Mammalian Protein Prep Kit (Qiagen, Valencia, CA, USA; 37901) according to the manufacturer's protocol, and then supplemented with Complete Protease Inhibitor Cocktail (Roche, Indianapolis, IN, USA). Equal amounts of tissue or cell lysates were separated on SDS-PAGE and then immunoblotted with antibodies that recognize ATG5 (Novus Biologicals, NB110-53818), ATG7 (Cell Signaling, Danvers, MA, USA; 2631), SQSTM1/p62 (American Research Products, Waltham, MA, USA; 03-GP62-C), MAP1LC3 (Nanotools, München, Germany; 0231-100/LC3-5F10), CDKN1A/p21 (Santa Cruz Biotechnology, Dallas, TX, USA; sc-397) MUCIN10 (MyBiosource, San Diego, CA, USA; MBS422856), KALLIKREIN1 (Boster Biological, Pleasanton, CA, USA; PA1709), CASPASE-3 (Cell Signaling, 9665), p53 (Santa Cruz Biotechnology, sc-6243), phospho-p53 (Cell Signaling, 9284), p38 (Cell Signaling, 9212), phospho-p38 (Cell Signaling, 9211), Actin (EMD Millipore, Billerica, MA, USA; MAB1501R), and GAPDH (Santa Cruz Biotechnology, sc-25778). Blots were visualized using an enhanced chemiluminescence detection kit (ECL-Plus, GE Healthcare, Pittsburgh, PA, USA; RPN2132) and a VersaDoc 5000 Imaging System (Bio-Rad) as we described previously. ${ }^{50}$ Signal intensities of the captured images were analyzed with the Quantity One Software (Bio-Rad). Results of western blots shown are representatives of two to four independent experiments.

Quantitation of TNF- $\boldsymbol{a}$. Tissue lysates were diluted ten-fold with 1X Assay Diluent B and levels of TNF- $\alpha$ were determined by the TNF alpha Mouse ELISA Kit (Abcam, ab100747) following the manufacturer's protocol. 
SA- $\boldsymbol{\beta}$-gal Staining. Control and duct-ligated SMGs were embedded in OCT compound for cryosection and stained for SA- $\beta$-gal activity according to the manufacturer's protocol (Cell Signaling Technology, 9860). Tissue slides were counterstained with hematoxylin before mounting medium was applied. The $\mathrm{H}_{2} \mathrm{O}_{2^{-}}$ treated $\mathrm{m} 5-7$ and MEF cells were fixed in $2 \%$ fomaldehyde, $0.2 \%$ glutaraldehyde in PBS for $10 \mathrm{~min}$ at room temperature and stained for SA- $\beta$-gal activity as above.

In situ apoptosis detection. Apoptosis was detected in FFPE tissue slides (prepared as described above) using an ApopTag Peroxidase In Situ Apoptosis Detection Kit (EMD Millipore, S7100) following the manufacturer's instructions. The percentage of apoptotic cells was calculated by dividing the number of ApopTagpositive cells over total number of nuclei enumerated from randomly selected ten microscopic fields (10X) of individual samples using ImagePro.

Statistical analysis. Gene expression data from quantitative RT-PCR were processed by Microsoft Excel, and analyzed by using GraphPad Prism 6.0 (GraphPad Software, La Jolla, CA, USA). The non-parametric Mann-Whitney test was employed to determine the significant differences between the ligated groups and control group of each genotype as well as the significant differences between $\operatorname{Atg}^{W^{W T}}$ and $A \operatorname{tg} 5^{\mathrm{KO}}$ mice. Statistic significance of in situ apoptosis assays between $A \operatorname{Atg} 5^{\mathrm{WT}}$ and $\operatorname{Atg}^{\mathrm{K}^{\mathrm{KO}}}$ groups was determined using Student's $t$-test. For cell viability assay, data were analyzed with ANOVA followed by Bonferroni $t$-test.

\section{Conflict of Interest}

The authors declare no conflict of interest.

Acknowledgements. We are sincerely grateful to Drs. Chih-Pin Liu, Mei-Ling Kuo and Peiguo Chu for their valuable reagents, helpful suggestions and critical reading of manuscript. This work was supported in part by National Institute of Health Research Grants R01DE10742 and R01DE14183 (to DKA), RC1DE020335 (to DKA and KHL). We also thank Ms. Sofia Loera of Pathology Core at City of Hope for immunohistochemical analyses, members of Animal Resources at City of Hope, members of Ann's laboratory for helpful discussions, and Dr Margaret Morgan for editing. ZB is the Edgington Chair in Medicine, USC.

1. Mizushima N, Komatsu M. Autophagy: renovation of cells and tissues. Cell 2011; 147 728-741.

2. Shen HM, Codogno P. Autophagic cell death: Loch Ness monster or endangered species? Autophagy 2011; 7: 457-465.

3. Kuma A, Hatano M, Matsui M, Yamamoto A, Nakaya $\mathrm{H}$, Yoshimori $\mathrm{T}$ et al. The role of autophagy during the early neonatal starvation period. Nature 2004; 432: 1032-1036.

4. Hara T, Nakamura K, Matsui M, Yamamoto A, Nakahara Y, Suzuki-Migishima R et al. Suppression of basal autophagy in neural cells causes neurodegenerative disease in mice. Nature 2006; 441: 885-889.

5. Taneike M, Yamaguchi O, Nakai A, Hikoso S, Takeda T, Mizote I et al. Inhibition of autophagy in the heart induces age-related cardiomyopathy. Autophagy 2010; 6: 600-606.

6. Takamura A, Komatsu M, Hara T, Sakamoto A, Kishi C, Waguri S et al. Autophagy-deficient mice develop multiple liver tumors. Genes Dev 2011; 25: 795-800.

7. White E, Lowe SW. Eating to exit: autophagy-enabled senescence revealed. Genes Dev 2009; 23: 784-787.

8. Rodier F, Campisi J. Four faces of cellular senescence. J Cell Biol 2011; 192: 547-556.

9. Kang HT, Lee KB, Kim SY, Choi HR, Park SC. Autophagy impairment induces premature senescence in primary human fibroblasts. PLOS One 2011; 6: e23367.

10. Kong X, Feng D, Wang H, Hong F, Bertola A, Wang FS et al. Interleukin-22 induces hepatic stellate cell senescence and restricts liver fibrosis in mice. Hepatology 2012; 56: 1150-1159.

11. Krizhanovsky V, Yon M, Dickins RA, Hearn S, Simon J, Miething C et al. Senescence of activated stellate cells limits liver fibrosis. Cell 2008; 134: 657-667.

12. Rubinsztein DC, Marino G, Kroemer G. Autophagy and aging. Cell 2011; 146: 682-695.

13. Salama R, Sadaie M, Hoare M, Narita M. Cellular senescence and its effector programs. Genes Dev 2014; 28: 99-114

14. Bozorgi SS, Proctor GB, Carpenter GH. Rapamycin delays salivary gland atrophy following ductal ligation. Cell Death Dis 2014; 5: e1146.

15. Silver N, Proctor GB, Arno M, Carpenter GH. Activation of mTOR coincides with autophagy during ligation-induced atrophy in the rat submandibular gland. Cell Death Dis 2010; 1: e14

16. Morgan-Bathke M, Lin HH, Chibly AM, Zhang W, Sun X, Chen $\mathrm{CH}$ et al. Deletion of ATG5 shows a role of autophagy in salivary homeostatic control. J Dent Res 2013; 92 : 911-917

17. Flodby P, Borok Z, Banfalvi A, Zhou B, Gao D, Minoo P et al. Directed expression of Cre in alveolar epithelial type 1 cells. Am J Respir Cell Mol Biol 2010; 43: 173-178.
18. Fritsch A, Loeckermann S, Kern JS, Braun A, BosI MR, Bley TA et al. A hypomorphic mouse model of dystrophic epidermolysis bullosa reveals mechanisms of disease and response to fibroblast therapy. J Clin Invest 2008; 118: 1669-1679.

19. Criscimanna A, Speicher JA, Houshmand G, Shiota C, Prasadan K, Ji B et al. Duct cells contribute to regeneration of endocrine and acinar cells following pancreatic damage in adult mice. Gastroenterology 2011; 141: 1451-1462 1462 e1451-1456.

20. Okumura K, Nakamura K, Hisatomi Y, Nagano K, Tanaka Y, Terada K et al. Salivary gland progenitor cells induced by duct ligation differentiate into hepatic and pancreatic lineages. Hepatology 2003; 38: 104-113.

21. Hai B, Yang Z, Millar SE, Choi YS, Taketo MM, Nagy A et al. Wnt/beta-catenin signaling regulates postnatal development and regeneration of the salivary gland. Stem Cells Dev 2010; 19: 1793-1801

22. Hosokawa N, Hara Y, Mizushima N. Generation of cell lines with tetracycline-regulated autophagy and a role for autophagy in controlling cell size. FEBS Lett 2006; 580: 2623-2629.

23. Coppe JP, Desprez PY, Krtolica A, Campisi J. The senescence-associated secretory phenotype: the dark side of tumor suppression. Annu Rev Pathol 2010; 5: 99-118.

24. Dimri GP, Lee X, Basile G, Acosta M, Scott G, Roskelley C et al. A biomarker that identifies senescent human cells in culture and in aging skin in vivo. Proc Natl Acad Sci USA 1995; 92: 9363-9367.

25. Campisi J, d'Adda di Fagagna F. Cellular senescence: when bad things happen to good cells. Nat Rev Mol Cell Biol 2007; 8: 729-740.

26. Takahashi S, Nakamura S, Suzuki R, Islam N, Domon T, Yamamoto T et al. Apoptosis and mitosis of parenchymal cells in the duct-ligated rat submandibular gland. Tissue Cell 2000; 32: 457-463.

27. Rankin MM, Wilbur CJ, Rak K, Shields EJ, Granger A, Kushner JA. beta-Cells are not generated in pancreatic duct ligation-induced injury in adult mice. Diabetes 2013; 62 : 1634-1645

28. Liu Y, Shoji-Kawata S, Sumpter RM Jr., Wei Y, Ginet V, Zhang $L$ et al. Autosis is a Na+,K +-ATPase-regulated form of cell death triggered by autophagy-inducing peptides, starvation, and hypoxia-ischemia. Proc Natl Acad Sci USA 2013; 110: 20364-20371.

29. Marino G, Niso-Santano M, Baehrecke EH, Kroemer G. Self-consumption: the interplay of autophagy and apoptosis. Nat Rev Mol Cell Biol 2014; 15: 81-94.

30. Rubinstein AD, Kimchi A. Life in the balance-a mechanistic view of the crosstalk between autophagy and apoptosis. J Cell Sci 2012; 125: 5259-5268.

31. Jiang $M$, Wei Q, Dong G, Komatsu M, Su Y, Dong Z. Autophagy in proximal tubules protects against acute kidney injury. Kidney Int 2012; 82: 1271-1283.

32. Maskey D, Yousefi S, Schmid I, Zlobec I, Perren A, Friis R et al. ATG5 is induced by DNA-damaging agents and promotes mitotic catastrophe independent of autophagy. Nat Commun 2013; 4: 2130.

33. Varma H, Gangadhar NM, Letso RR, Wolpaw AJ, Sriramaratnam R, Stockwell BR. Identification of a small molecule that induces ATG5-and-cathepsin-I-dependent cell death and modulates polyglutamine toxicity. Exp Cell Res 2013; 319: 1759-1773.

34. Yousefi S, Perozzo R, Schmid I, Ziemiecki A, Schaffner T, Scapozza L et al. Calpainmediated cleavage of Atg5 switches autophagy to apoptosis. Nat Cell Biol 2006; 8: 1124-1132.

35. Bringold F, Serrano M. Tumor suppressors and oncogenes in cellular senescence. Exp Gerontol 2000; 35: 317-329.

36. Chen $\mathrm{Q}$, Ames $B N$. Senescence-like growth arrest induced by hydrogen peroxide in human diploid fibroblast F65 cells. Proc Natl Acad Sci USA 1994; 91: 4130-4134.

37. Baker DJ, Perez-Terzic C, Jin F, Pitel KS, Niederlander NJ, Jeganathan K et al. Opposing roles for p16lnk4a and p19Arf in senescence and ageing caused by BubR1 insufficiency. Nat Cell Biol 2008; 10: 825-836.

38. Braig M, Lee S, Loddenkemper C, Rudolph C, Peters AH, Schlegelberger B et al. Oncogene-induced senescence as an initial barrier in lymphoma development. Nature 2005; 436: $660-665$

39. Chen Z, Trotman LC, Shaffer D, Lin HK, Dotan ZA, Niki M et al. Crucial role of p53-dependent cellular senescence in suppression of Pten-deficient tumorigenesis. Nature 2005; 436: 725-730

40. Keyes WM, Wu Y, Vogel H, Guo X, Lowe SW, Mills AA. p63 deficiency activates a program of cellular senescence and leads to accelerated aging. Genes Dev 2005; 19: 1986-1999.

41. Tyner SD, Venkatachalam S, Choi J, Jones S, Ghebranious N, Igelmann H et al. p53 mutant mice that display early ageing-associated phenotypes. Nature 2002; 415: 45-53.

42. Gewirtz DA. Autophagy and senescence: a partnership in search of definition. Autophagy 2013; 9: 808-812.

43. Fujii S, Hara H, Araya J, Takasaka N, Kojima J, Ito S et al. Insufficient autophagy promotes bronchial epithelial cell senescence in chronic obstructive pulmonary disease. Oncoimmunology 2012; 1: 630-641.

44. Bjorkoy G, Lamark T, Brech A, Outzen H, Perander M, Overvatn A et al. p62/SQSTM1 forms protein aggregates degraded by autophagy and has a protective effect on huntingtininduced cell death. J Cell Biol 2005; 171: 603-614.

45. Korolchuk VI, Mansilla A, Menzies FM, Rubinsztein DC. Autophagy inhibition compromises degradation of ubiquitin-proteasome pathway substrates. Mol Cell 2009; 33: 517-527.

46. Kuilman T, Michaloglou C, Mooi WJ, Peeper DS. The essence of senescence. Genes Dev 2010; 24: 2463-2479.

47. Jung $\mathrm{CH}$, Ro SH, Cao J, Otto NM, Kim DH. mTOR regulation of autophagy. FEBS Lett 2010; 584: 1287-1295. 
48. Weng DY, Zhang Y, Hayashi Y, Kuan CY, Liu CY, Babcock G et al. Promiscuous recombination of LoxP alleles during gametogenesis in cornea Cre driver mice. Mol Vis 2008; 14: 562-571.

49. Muzumdar MD, Tasic B, Miyamichi K, Li L, Luo L. A global double-fluorescent Cre reporter mouse. Genesis 2007; 45: 593-605.

50. Lin HH, Li X, Chen JL, Sun X, Cooper FN, Chen YR et al. Identification of an AAA ATPase VPS4B-dependent pathway that modulates epidermal growth factor receptor abundance and signaling during hypoxia. Mol Cell Biol 2012; 32: 1124-1138.

51. Lin TC, Chen YR, Kensicki E, Li AY, Kong M, Li Y et al. Autophagy: resetting glutamine-dependent metabolism and oxygen consumption. Autophagy 2012; 8: 1477-1493.

52. Yang $T T$, Sinai $P$, Kain $S R$. An acid phosphatase assay for quantifying the growth of adherent and nonadherent cells. Anal Biochem 1996; 241: 103-108.

53. Jayasinghe NR, Cope GH, Jacob S. Morphometric studies on the development and sexual dimorphism of the submandibular gland of the mouse. J Anat 1990; 172: 115-127.
54. Turner JT, Weisman GA, Camden JM. Upregulation of P2Y2 nucleotide receptors in rat salivary gland cells during short-term culture. Am J Physiol 1997; 273: C1100-C1107.

\section{(c) (i)}

Cell Death and Disease is an open-access journal published by Nature Publishing Group. This work is licensed under a Creative Commons Attribution 4.0 International Licence. The images or other third party material in this article are included in the article's Creative Commons licence, unless indicated otherwise in the credit line; if the material is not included under the Creative Commons licence, users will need to obtain permission from the licence holder to reproduce the material. To view a copy of this licence, visit http://creativecommons.org/licenses/by/4.0

Supplementary Information accompanies this paper on Cell Death and Disease website (http://www.nature.com/cddis) 